\title{
Cancer du sein, cérébellite et méningite carcinomateuse
}

\section{Breast cancer, cerebellitis and carcinomatous meningitis}

\author{
T. Pernin $\cdot$ O. Peyrony $\cdot$ P. Taboulet
}

Reçu le 3 mai 2012 ; accepté le 29 mai 2012

(C) SFMU et Springer-Verlag France 2012

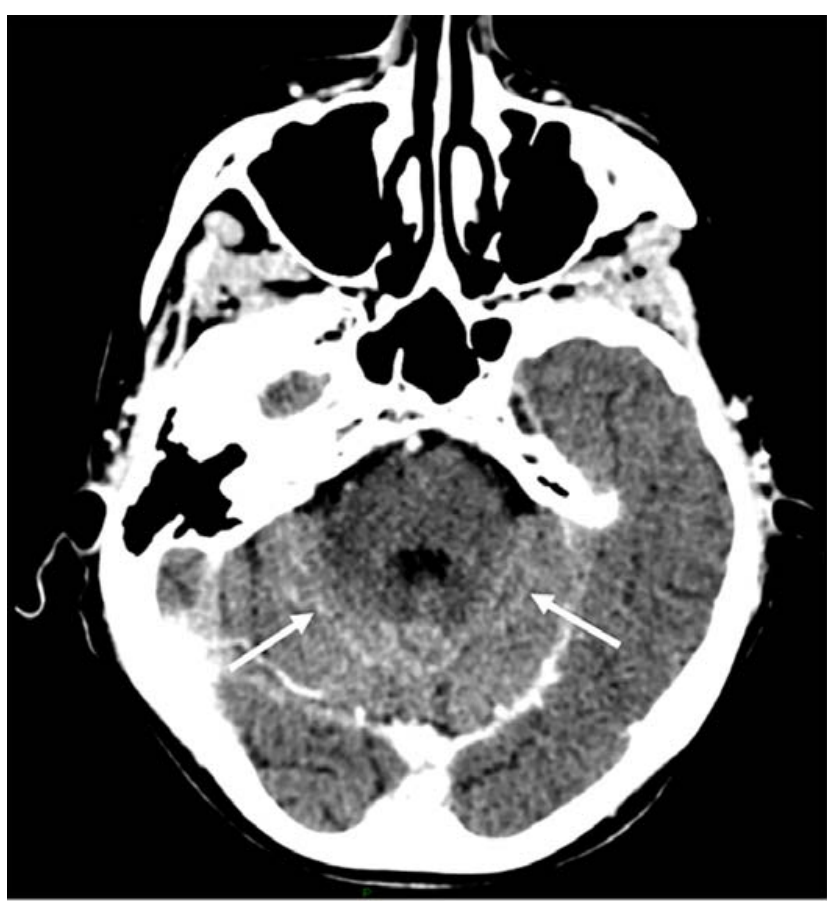

Fig. 1 Scanner cérébral : prise de contraste leptoméningée cérébelleuse bilatérale

Une femme de 74 ans suivie pour un cancer du sein se présente aux urgences pour dysarthrie et instabilité posturale. L'examen clinique objective une dysarthrie et une ataxie cérébelleuses.

Le scanner (Fig. 1), réalisé afin d'éliminer une métastase cérébrale, et l'IRM avec injection de Gadolinium (Fig. 2)

T. Pernin $(\bowtie)$

Université Paris VII, UFR de médecine, Site Villemin,

10, avenue de Verdun, F-75010 Paris, France

e-mail : thomas.prototype@gmail.com

\section{O. Peyrony $\cdot$ P. Taboulet}

Service des urgences, hôpital Saint-Louis,

Assistance publique-hôpitaux de Paris, Université Denis Diderot,

1, avenue Claude Vellefaux, F-75010 Paris, France

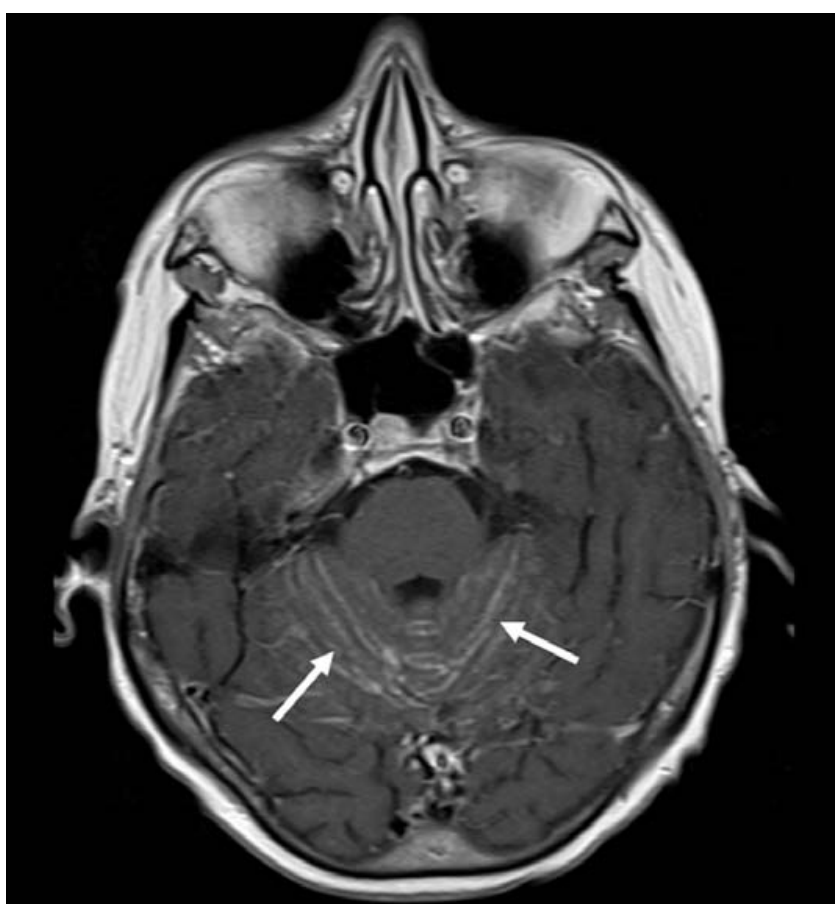

Fig. 2 IRM cérébrale, T1, coupe axiale : prise de contraste leptoméningée cérébelleuse bilatérale

révèlent une prise de contraste leptoméningée cérébelleuse évocatrice de méningite carcinomateuse.

Ces deux examens peuvent suffire à porter ce diagnostic si la clinique est fortement évocatrice. En particulier, l' IRM cérébral avec injection de gadolinium est l'examen de choix car il a prouvé une meilleure sensibilité que le scanner dans ce contexte [1]. Le diagnostic de méningite carcinomateuse a été confirmé chez cette patiente par une ponction lombaire qui est l'examen de référence.

\section{Référence}

1. Schumacher M, Orszagh M (1998) Imaging techniques in neoplastic meningiosis. J Neuro Oncol 38:111-20 